\title{
0769 COMMUTING ROAD TRAFFIC ACCIDENTS IN CROATIA
}

I Kolcic*, A V Jovic, U Rodin, I Brkic Bilos, N Antoljak, 0 Polasek Correspondence: Andrija Stampar School of Public Health, Medical School, University of Zagreb, Rockefellerova 4, Zagreb, 10000, Croatia

\subsection{6/ip.2010.029215.769}

The aim of the study was to investigate risk factors associated with commuting road traffic accidents (RTA) in Croatia. A total of 1138 persons hospitalised for various accidents were surveyed in this cross-sectional study. Data were collected from 23 hospitals from all parts of Croatia during March-May 2008. The questionnaire encompassed personal data, socioeconomic status, lifestyle determinants and health status prior to accident. This was supplemented with circumstances for RTA: time and place of the accident, mode of transportation, traffic role, accident situation, road and light condition. Data were coded according to NOMESCO classification system. $\chi^{2}$ Test was used in the analysis. A total of 283 were injured in RTA. Almost a half ( $\mathrm{N}=118,42.6 \%)$ were injured while commuting. We did not detect any difference between commuters and other RTA victims in terms of age group, gender, employment class, accident situation or type of vehicle. Significant difference in road track conditions was detected, with more accidents occurring in unfavourable road conditions among non-commuting RTA victims $(\mathrm{p}<0.001)$. Also, commuting accidents were more common during daytime $(p=0.003)$. Most of commuting accidents were reported on Thursdays and Saturdays, without significant difference between commuting and non-commuting RTAs. These results describe a general pattern of commuting RTAs in Croatia, enabling the 


\section{IP Safety 2010 abstracts}

development of a framework for future studies. The framework would determine priorities for work-related road safety management, as well as develop policies and interventions aiming to reduce RTAs and their consequences. 